\title{
RECENT RESEARCH ON THE DESIGN AND BEHAVIOUR OF DRIVE-IN STEEL STORAGE RACKING SYSTEMS
}

\author{
Benoit P. Gilbert ${ }^{\mathrm{a}}$, Kim J.R. Rasmussen ${ }^{\mathrm{b}}$ \\ ${ }^{a}$ School of Civil Engineering, The University of Sydney, Australia (now, School of Engineering, Griffith Univer- \\ sity, Australia) \\ ${ }^{\mathrm{b}}$ School of Civil Engineering, The University of Sydney, Australia
}

\begin{abstract}
The paper summarises a recently completed research program carried out at the University of Sydney on drive-in steel storage racks subject to horizontal impact loads. Impact loads develop frequently during the normal operation of drive-in racks when the forklift truck strikes an upright on entering or exiting a bay, and may lead to local or global collapse. The collapse follows the bowing of the upright which may cause a pallet to drop off the supporting beam rails and initiate progressive collapse down through the bay and possibly into adjacent bays as well.

The research program comprised full-scale tests on assemblies of a 4-bay wide racking system, tests of components of the system, the development of finite element models capable of accurately predicting the behaviour of the system, parametric studies of the strength and stiffness of steel storage racks, the development of a simple mechanical model for understanding the dynamic behaviour of the system during impact and a reliability analysis for deriving equations for the design impact loads and associated load factors.

The purpose of the paper is to give an overview of the methodology adapted for the research program and to present the main findings and final outcomes of the research.
\end{abstract}

\section{INTRODUCTION}

Steel storage racks are used extensively in industry for storing goods. They are freestanding and act as structures in their own right. Different types of racks are available on the market and are described in [1]. "Selective racks", the most common type of rack, are separated by aisles and each pallet is always accessible. On the other hand, "drive-in" racks, require less floor space by storing pallets on rail beams, one after the other, with no space between them. The forklift truck drives into the rack and stores pallets on the first-in, last-out principle. With the increasing price of land, drive-in racks are often a more economical solution than selective racks when storing the same good. An example of drive-in racks is shown in Fig. 1. Driveracks are typically 3 to 7 pallets deep resulting in a complex slender structure with poorly understood 3D behaviour and increased risk of collapse.

To allow forklift passage, drive-in racks can only be braced at the back (spine bracing) and at the top (plan bracing). Consequently, uprights have substantial unbraced lengths and are prone to buckling in the down-aisle direction. Structural collapse is known to occur in drive-in racks as a result of the accidental impact by forklift trucks during entry or exit of bays. While entering or exiting the rack, the forklift truck driver may misjudge the location of the truck 
and start turning before the pallet is cleared of the rack. The forklift truck, by typically rotating about its front wheel axis, causes the pallet to swing and impacts with the front upright of the rack. The upright will bend and failure occur if the upright bends sufficiently for the pallet not to be supported by the rail beams as shown in Fig. 2 .

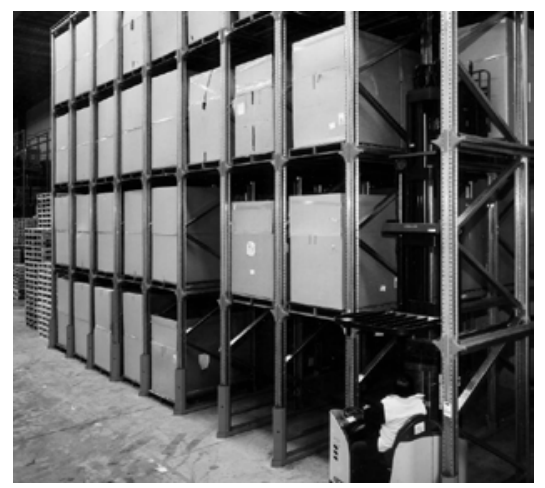

Fig. 1: Example of drive-in rack

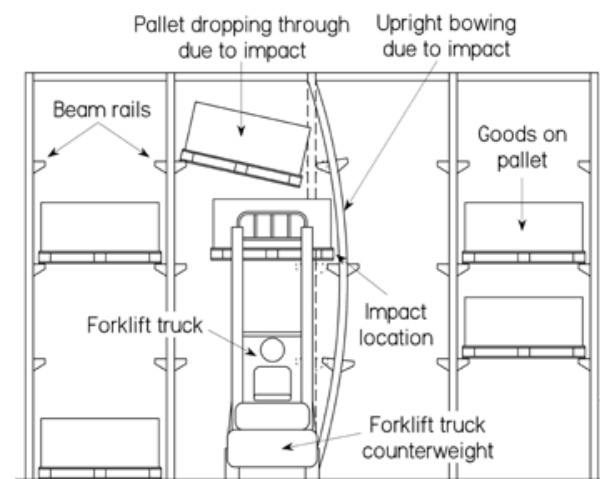

Fig. 2: Drop through failure mode

The main racking design codes, RMI (Rack Manufacturers Institute) [2], EN15512 [3] and AS 4084 (Australian Standard) [4] apply to selective racks and not to drive-in racks. The SEMA (Storage Equipment Manufacturers' Association) publication [5] mentions drive-in racks but is not explicit in defining design procedures. A European code on drive-in racks (FEM 10.2.07 [6]) is currently being developed but is not available yet.

Few tests have been performed on drive-in racks and were mainly conducted on parts of the structure considering vertical loading. Murray [7] studied the critical load of a drive-in rack column and compared the theoretical formula against a simple single column test. Dunai et al. [8] tested a 2 bay wide, 2 pallet deep and 3 or 5 storey high (i.e. 2 or 4 beam rail levels) rack. The rack was braced at the back (spine bracing) and at the top (plan bracing). The rack represented a compact complete system although it was not loaded by means of pallets, and so did not consider the potentially significant influence pallets may have on the 3D rack behaviour by acting as horizontal bracing members [9]. Freitas et al. [10-11] tested a 2 bay wide, 1 pallet deep and 2 storey high (i.e. 1 rail beam level) rack. The rack was only braced at the top (plan bracing) and was more representative of a drive-through rack than a drive-in rack.

This paper summarises a recent research program on drive-in racks subject to horizontal impact loads [12]. Static and dynamic tests were performed on a complete system to determine (i) the overall stiffness and 3D behaviour of the system and (ii) the stiffness and damping characteristics and transient dynamic response when subjected to horizontal impact loads. Tests were also performed on components of the frame to determine the behaviour and strength of connections and upright frames. Detailed finite element models were calibrated against the tests and shown to provide accurate predictions of deflections and ultimate strength. A reliability analysis concluded the study leading to design equations for the impact loads and load factors to use in the design of drive-in racks. The main parts of the research are summarised in this paper with particular emphasis on the development of mechanical models representing the forklift truck and rack system.

\section{THE FORKLIFT TRUCK}

This section develops a simple model of a loaded forklift truck based on first principles of mechanics. Model masses, as well as stiffness and damping coefficients are determined from experimental results obtained from isolated tests of an actual forklift truck. Comparisons be- 
tween experimental results and solutions obtained from the simple mechanical model show that it accurately reproduces the static and dynamic behaviours of the forklift truck.

\subsection{Static and dynamic test set-up on forklift truck}

Tests were performed on a NICHIYU FB20 forklift truck model with 2 tons load capacity in order to measure its static and dynamic behaviour under horizontal loading. Three different loads (300 kgs, $775 \mathrm{kgs}$ and $1175 \mathrm{kgs)} \mathrm{were} \mathrm{placed} \mathrm{sequentially} \mathrm{on} \mathrm{a} \mathrm{pallet,} \mathrm{with} \mathrm{the} \mathrm{centre}$ line of the pallet located at a vertical distance $H$ above the pivot of the mast. The mast was attached near the base of the truck and hence, the height $H$ could be taken as the impact elevation in the tests presented in Section 3.2. A hydraulic jack with a quick release system applied a horizontal load in the impact direction at the location of the impact point. Two LVDTs recorded the horizontal displacements of the pallet at the jack location and of the forklift truck mast at the jack elevation.

In the first part of the test, the jack pulled statically on the pallet at a low displacement rate and the static stiffness of the forklift truck was recorded. In the second part, the load was quickly released leaving the system free to oscillate while recording the dynamic behaviour of the truck. See [13-14] for more information on the test set-up.

\subsection{Static mechanical model}

In most forklift truck models, the mast of a forklift truck is attached to the forklift truck body at two distinct points. A bottom hinge at the level of the front wheel axis allows the mast to rotate forward and backward while restraining the mast from rotating sideway. Two "tilt hydraulic jacks", positioned at a height $h$ above the bottom hinge and on each side of the mast, control the tilting motion about the bottom hinge.

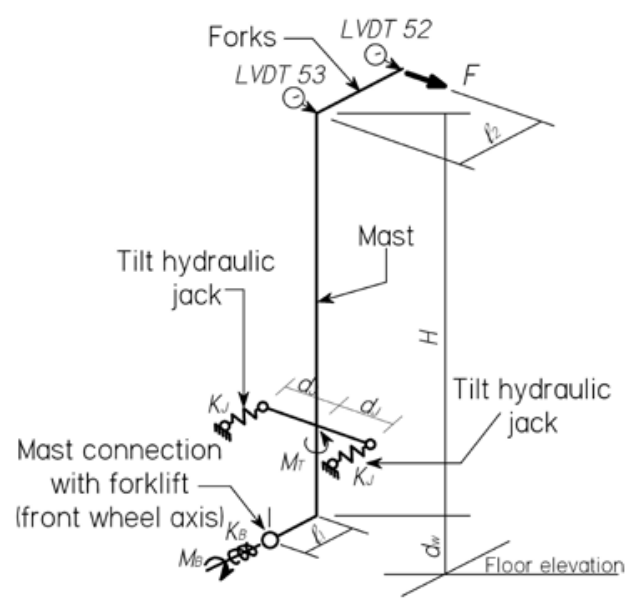

Fig. 3: Forklift truck static mechanical model

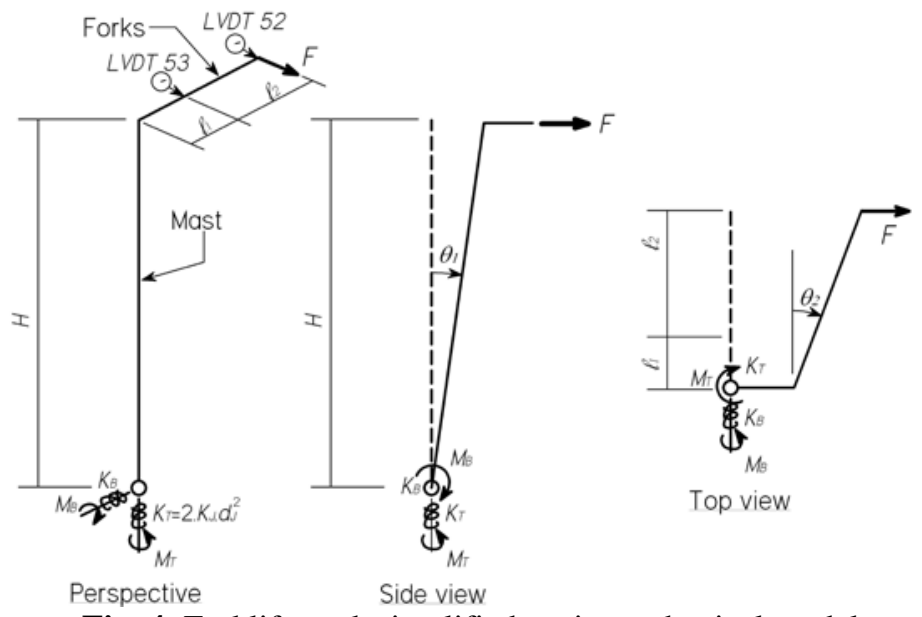

Fig. 4: Forklift truck simplified static mechanical model

Figure 3 presents a simple model of the forklift truck, in which a vertical member at a horizontal distance $\ell_{1}$ from the bottom hinge represents the mast and a horizontal member at a vertical distance $H$ from the base of the mast represents the forks. A rotational stiffness $k_{B}$, representing the rotational stiffness of the bottom hinge combined with the rotational stiffness provided by the forklift truck shock absorbers, elastically restrains the mast from rotating sideway about its base. Two horizontal springs with stiffness $k_{J}$, located at a distance $d_{J}$ on each side of the mast, represent the tilt hydraulic jacks and elastically restrain the mast against torsion. Due 
to the nature of their connections with the mast, the two tilt hydraulic jacks are considered to be pinned at theirs extremities, unable to transfer shear. The location of the LVDTs (LVDTs 52 and 53) used in the experimental set-up is shown in Fig. 3.

The system in Fig. 3 is simplified to the statically equivalent model shown in Fig. 4, in which the tilt hydraulic jacks are replaced by an equivalent single torsional spring with stiffness $k_{T}$, while the bending stiffness $k_{B}$ is unchanged. The stiffness terms $k_{B}$ and $k_{T}$ are obtained from the tests using the relationships,

$$
M_{B}=k_{B} \theta_{1}=F H \text { and } M_{T}=k_{T} \theta_{2}=F\left(\ell_{1}+\ell_{2}\right)
$$

in which $M_{B}$ and $M_{T}$ are the bending and torsional moments induced by the jack force $F$ respectively, $l_{1}$ is the horizontal distance from the forklift truck front wheel axis to the centreline of the mast and $\ell_{2}$ is the horizontal distance from the centreline of the mast to the impact point. $\theta_{1}$ and $\theta_{2}$ represent the bending and torsional angles respectively, as shown in Fig. 4. For small displacements, the stiffness terms $k_{B}$ and $k_{T}$ are calculated from the recorded displacements $\delta_{52}$ and $\delta_{53}$ of LVDTs 52 and 53 respectively as,

$$
k_{B}=\frac{F H^{2}}{\delta_{53}\left(1+\frac{\ell_{1}}{\ell_{2}}\right)-\delta_{52} \frac{\ell_{1}}{\ell_{2}}} \text { and } k_{T}=\frac{F\left(\ell_{1}+\ell_{2}\right) \ell_{2}}{\delta_{52}-\delta_{53}}
$$

Table 1 gives the average values of $k_{B}$ and $k_{T}$ found for three tests per pallet load with test set-up values of $H=2425 \mathrm{~mm}, \ell_{1}=200 \mathrm{~mm}$ and $\ell_{2}=1230 \mathrm{~mm}$. Detailed test results are given in [13].

\begin{tabular}{|c|c|c|c|c|c|c|c|c|c|}
\hline & \multirow{2}{*}{\multicolumn{3}{|c|}{ Load $=300 \mathrm{~kg}$}} & & & & & & \\
\hline & & & & \multicolumn{3}{|c|}{ Load $=775 \mathrm{~kg}$} & \multicolumn{3}{|c|}{ Load $=1175 \mathrm{~kg}$} \\
\hline & $\begin{array}{c}k_{B} \\
\text { (kN.mm/rad) }\end{array}$ & $\begin{array}{c}k_{T} \\
\mathrm{kN} . \mathrm{mm} / \mathrm{rad})\end{array}$ & $\begin{array}{c}C_{T} \\
\left(\mathrm{kN} \cdot \mathrm{mm} \cdot \mathrm{s}^{2} \mathrm{rad}^{2}\right)\end{array}$ & $\begin{array}{c}k_{B} \\
\text { (kN.mm/rad) }\end{array}$ & $\begin{array}{c}k_{T} \\
\text { (kN.mm/rad) }\end{array}$ & $\begin{array}{c}C_{T} \\
\left(\mathrm{kN} . \mathrm{mm} \cdot \mathrm{s}^{2} / \mathrm{rad}^{2}\right)\end{array}$ & $\begin{array}{c}k_{B} \\
\text { kN.mm/rad) }\end{array}$ & $\begin{array}{c}k_{T} \\
\text { (kN.mm/rad) }\end{array}$ & $\begin{array}{c}C_{T} \\
\left(\mathrm{kN} \cdot \mathrm{mm} \cdot \mathrm{s}^{2} / \mathrm{rad}^{2}\right)\end{array}$ \\
\hline Average & 915278 & 88590 & 296667 & 835263 & 136256 & 683333 & 869715 & 148334 & 1266667 \\
\hline
\end{tabular}

Table 1: Forklift truck tests, stiffness and damping

It is observed from Table 1 that while the bending rotational stiffness $k_{B}$ is essentially constant with increasing pallet load, the torsional stiffness $k_{T}$ increases with pallet load. This increase is due to the increase in oil pressure in the tilt hydraulic jacks required to prevent the mast from tilting forward when increasing the pallet load. $k_{B}$ can be considered constant for all pallet loads and equal to its mean value of $873,418 \mathrm{kN} . \mathrm{mm} / \mathrm{rad}$, while linear interpolation can be performed in Table 1 to obtain the values of $k_{T}$ for given pallet loads (see [13-14]).

\subsection{Dynamic mechanical model}

The damping of the system and the mass $m$ representing the combined mass of the pallet, pallet load, and forks are added to the static model of the forklift truck in Fig. 4 to create a combined static and dynamic mechanical model shown in Fig. 5. The centre of mass $m$ is assumed to coincide with the centre of gravity of the pallet load, i.e. at a vertical distance $H_{C o G}$ from the base of the mast and a horizontal distance $\ell_{3}$ from the centreline of the mast. The pallet mass and the mass of the forks are estimated to be $50 \mathrm{kgs}$ each.

The damping was found to be of "drag force" type, i.e. proportional to the square of the velocity. The torsional damping $C_{T}$ from the tilt hydraulic jacks is considered to be the predominant source of energy loss and all other sources of damping are ignored. Calculated values of the torsional damping coefficient $C_{T}$ obtained from the experiment are given in Table 1. 


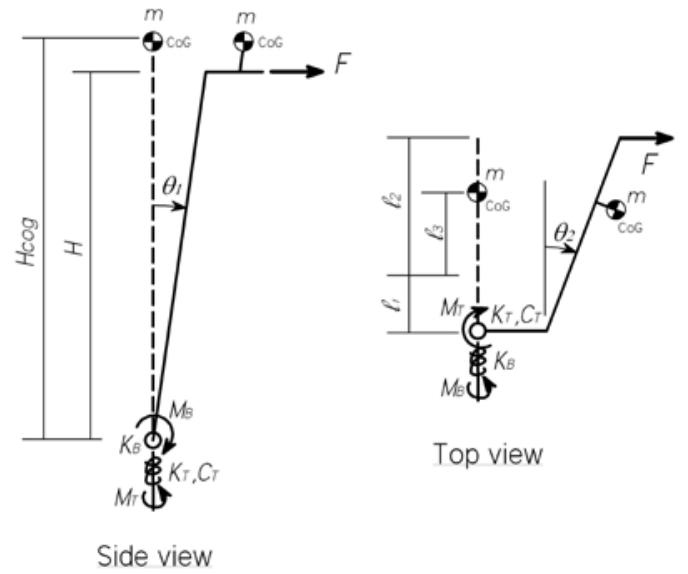

Fig. 5: Simplified static and dynamic mechanical model of forklift truck

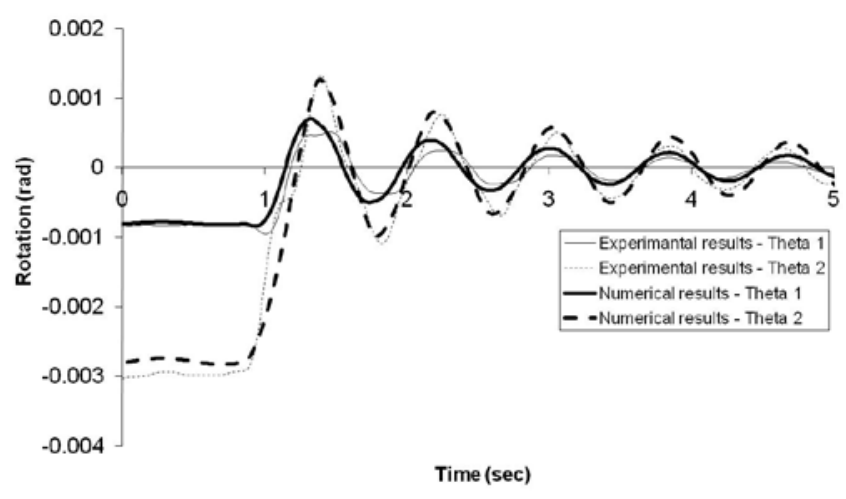

Fig. 6: Recorded and numerical values of $\theta_{1}$ and $\theta_{2}$; pallet load of $1175 \mathrm{kgs}$

The equations of motion for the mast rotations $\theta_{1}$ and $\theta_{2}$ under external loading are,

$$
\begin{gathered}
m H_{C o G}^{2} \ddot{\theta}_{1}+k_{B} \theta_{1}+m H_{C o G}\left(\ell_{1}+\ell_{3}\right) \ddot{\theta}_{2}=F H \\
m\left(\ell_{1}+\ell_{3}\right)^{2} \ddot{\theta}_{2}+k_{T} \theta_{2}+C_{T}\left|\dot{\theta}_{2}\right| \dot{\theta}_{2}+m H_{C o G}\left(\ell_{1}+\ell_{3}\right) \ddot{\theta}_{1}=F\left(\ell_{1}+\ell_{2}\right)
\end{gathered}
$$

Figure 6 plots the values of $\theta_{1}$ and $\theta_{2}$ obtained from a typical experimental test, as described in Section 2.1 (with a pallet load of $1175 \mathrm{kgs}$ ) and derived from Eqs. (3) and (4) respectively. Equations (3) and (4) are found to accurately reproduce the dynamic behaviour of the forklift truck, as shown in Fig. 6 (see [13] for all comparisons).

\section{THE RACK}

\subsection{Mechanical model}

Full scale tests on a drive-in rack system showed that when subjected to an impact force, the rack resists the impact by an overall displacement of the structure (stiffness $k_{o}$ ) and by bending of the impacted upright (stiffness $k_{u}$ ). This observation suggests the simple mechanical model of the rack shown in Fig. 7, where $m_{o}$ and $m_{u}$ represent the associated masses of the overall rack displacement and the impacted upright respectively, and $C_{o}$ and $C_{u}$ represent the damping coefficients of the overall rack and the impacted upright respectively. The stiffness terms $k_{o}$ and $k_{u}$, masses $m_{o}$ and $m_{u}$ and damping coefficients $C_{o}$ and $C_{u}$ are derived in Section 3.3, as determined from the experimental tests described in Section 3.2.

In Fig. 7, $F_{\text {imp }}$ represents the impact force on the rack, $x_{u}$ the displacement of mass $m_{u}$ and $x_{o}$ the displacement of mass $m_{o}$. The equations of motion for $x_{u}$ and $x_{o}$ of the system are,

$$
\begin{gathered}
m_{u} \ddot{x}_{u}+C_{u}\left(\dot{x}_{u}-\dot{x}_{o}\right)+k_{u}\left(x_{u}-x_{o}\right)=F_{\text {imp }} \\
m_{o} \ddot{x}_{o}+C_{o} \dot{x}_{o}+k_{o} x_{o}-C_{u}\left(\dot{x}_{u}-\dot{x}_{o}\right)-k_{u}\left(x_{u}-x_{o}\right)=0
\end{gathered}
$$

\subsection{Impact tests}

\subsubsection{Test set-up}

Experimental static and impact tests were conducted on a full-scale, 4-bay wide, 4-pallet deep and 3-rail beam elevation drive-in rack for the situation where the forklift truck impacts the rack in the down-aisle direction while exiting a bay. Representative operating conditions were achieved by placing 1.2 tons and 2 tons concrete blocks on wood pallets in the rack prior to the impact. Two loading patterns, or configurations, were tested, one corresponding to the 
forklift truck exiting an empty bay and one corresponding to the forklift truck exiting a nearly fully loaded bay.

Two LVDTs recorded displacements in the down-aisle direction of the impacted upright and of the directly opposite front upright. This set-up allows the measurement of the overall displacement of the rack at the impact point ( $x_{o}$ in Fig. 7) and the total displacement of the impacted upright ( $x_{u}$ in Fig. 7). The upright bending displacement $x_{u}-x_{o}$ represents the bay opening at the impact point, and the possibility of a pallet dropping through. Figure 8 shows the test set-up and positions of the LVDTs.

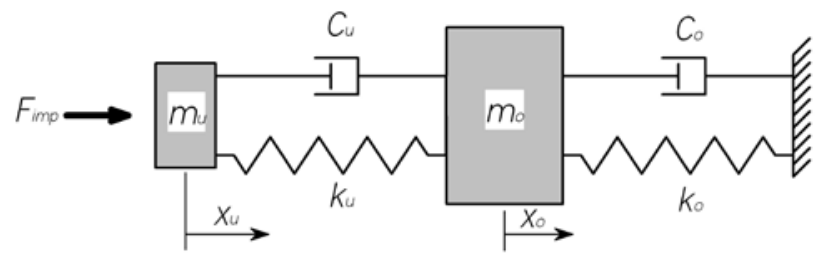

Fig. 7: Static and dynamic mechanical model of drive-in rack

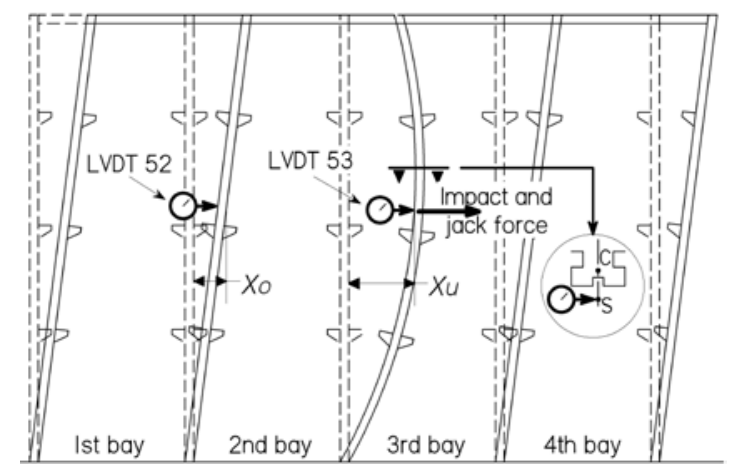

Fig. 8: Experimental test set-up

\subsubsection{Static tests}

The static series of tests investigated the stiffness of the overall rack $\left(k_{o}\right)$ and the impacted upright $\left(k_{u}\right)$ for loading in the down-aisle direction. A servo-controlled hydraulic jack was connected at the shear centre line of the impacted upright at the impact elevation and statically pulled on the rack at a low displacement rate (see Fig. 8). The stiffness terms $k_{o}$ and $k_{u}$ were determined from the test results as,

$$
k_{o}=\frac{F}{x_{o}}=\frac{F}{\delta_{52}} \text { and } k_{u}=\frac{F}{x_{u}-x_{o}}=\frac{F}{\delta_{53}-\delta_{52}}
$$

where $F$ is the force applied by the hydraulic jack and $\delta_{52}$ and $\delta_{53}$ are the horizontal down-aisle displacements obtained from LVDTs 52 and 53 respectively, see Fig. 8. Table 2 gives the initial stiffness values found for the two investigated loading configurations.

Table 2: Drive-in rack, static test results stiffness

\begin{tabular}{|c|c|c|c|}
\hline \multicolumn{2}{|c|}{$1^{\text {st }}$ loading configuration (empty bay) } & \multicolumn{2}{|c|}{$2^{\text {nd }}$ loading configuration (loaded bay) } \\
\hline$k_{o}(\mathrm{kN} / \mathrm{mm})$ & $k_{u}(\mathrm{kN} / \mathrm{mm})$ & $k_{o}(\mathrm{kN} / \mathrm{mm})$ & $k_{u}(\mathrm{kN} / \mathrm{mm})$ \\
\hline 0.762 & 0.300 & 0.694 & 1.124 \\
\hline
\end{tabular}

\subsubsection{Dynamic tests}

The dynamic series of tests comprised actual impact tests. Before each test, the forklift truck was positioned in the rack and reversed while turning about its front wheel axis to impact the desired upright with the edge of its pallet. Figure 9 shows photos of an actual test. For each loading configuration, 60 tests were performed representing 3 series of 20 tests each with the forklift truck carrying a $300 \mathrm{kgs}$, a $775 \mathrm{kgs}$ or a $1175 \mathrm{kgs}$ weight on the pallet.

Figure 10 plots the recorded front upright displacements $\left(x_{u}\right.$ and $\left.x_{o}\right)$ and bay opening $\left(x_{u}-\right.$ $x_{o}$ ) against time for a typical test. The transient response shown in the figure was typical and reproducible, although the amplitudes of $x_{u}$ and $x_{o}$ were found to vary randomly between tests of a same series due to the forklift truck being manually and not automatically operated. The complete set of test results are reported in [13]. 


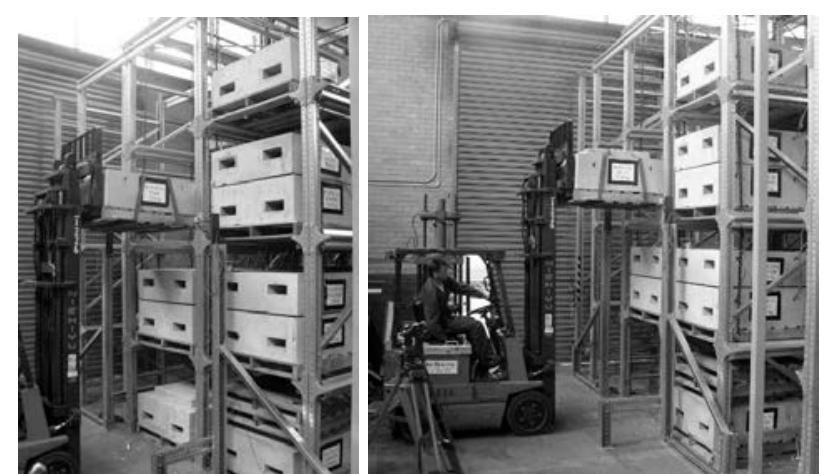

Fig. 9: Forklift truck impact tests

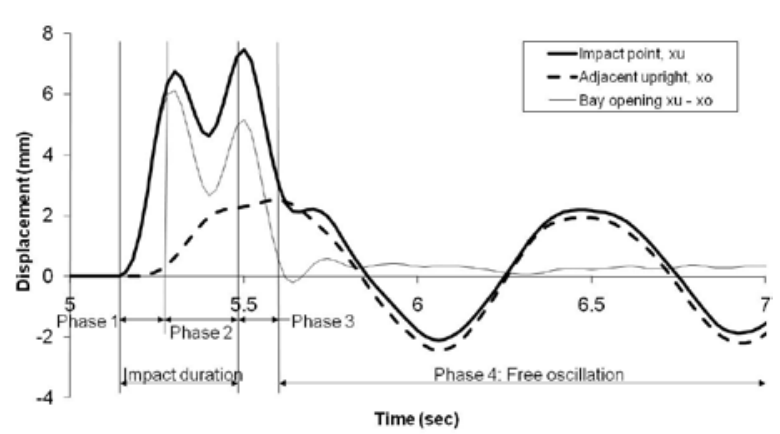

Fig. 10: Impact test results, $x_{\mathrm{u}}, \mathrm{x}_{0}$ and bay opening $\mathrm{x}_{\mathrm{u}}-\mathrm{x}_{0}$; pallet load of $1175 \mathrm{kgs}$

As illustrated in Fig. 10, the test results show that an impact can be separated into four distinct phases. During the first phase, the overall rack essentially stays stationary while the impacted upright starts bending, opening the bay to its maximum value. In the second phase, the overall rack starts its motion while the displacement at the impact point tends to reach a maximum, causing the bay opening to start decreasing. At one stage during the second phase, the pallet impacting the rack loses contact with the rack while $x_{u}$ and $x_{o}$ may still increase due to the inertia of the rack and of the impacted upright. In the third phase, the impacted upright bends back to its neutral position, and the rack is then free to oscillate during the fourth and last phase. As a result of the large amount of frictional damping between the pallets and the beam rails, the impacted upright does not oscillate and $x_{u}-x_{o}$ is essentially zero during the fourth phase.

One can deduce that if the bay opens sufficiently to trigger failure, such failure is likely to happen during the critical first phase of the impact where the bay opening reaches its maximum. This phase lasts about $0.15 \mathrm{sec}$.

\subsection{Calibration of mechanical model}

While the stiffness terms $k_{o}$ and $k_{u}$ were determined from the static tests described in Section 3.2.2, the masses $m_{\mathrm{u}}$ and $m_{\mathrm{o}}$, and damping coefficients $C_{o}$ and $C_{u}$ were determined from the dynamic tests. The equivalent mass of the overall system $m_{o}$ was calculated from Eq. (8) with the natural period $T_{o}$ obtained from a Fourier transform on the rack displacement response $\left(x_{o}\right)$ during free oscillations,

$$
m_{o}=k_{o}\left(\frac{T_{o}}{2 \pi}\right)^{2}
$$

The same response, combined with the logarithmic decrement method, was used to determine the equivalent damping of the overall system $C_{o}$.

The damping of the impacted upright $C_{u}$ is obtained from Eq. (6) by averaging the values of $C_{u}$ calculated for each experimental recording step $\Delta t$ over the first phase of the impact (see [13]). The equivalent mass of the impacted upright $m_{u}$ cannot satisfactory be obtained from the equations of motion and has been estimated for each loading configuration and from the mass associated with the relative displacement $x_{u}-x_{o}$ of the upright. Average values of $m_{o}, m_{u}$, $C_{o}$ and $C_{u}$ are reported in Table 3. 
Table 3: Summary of $m_{o}, m_{u}, C_{o}$ and $C_{u}$

\begin{tabular}{cccc|cccc}
\hline \multicolumn{3}{c|}{$1^{\text {st }}$ loading configuration (empty bay) } & \multicolumn{4}{c}{$2^{\text {nd }}$ loading configuration (loaded bay) } \\
$m_{o}(\mathrm{~kg})$ & $C_{o}(\mathrm{kN} /(\mathrm{mm} / \mathrm{s}))$ & $m_{u}(\mathrm{~kg})$ & $C_{u}(\mathrm{kN} /(\mathrm{mm} / \mathrm{s}))$ & $m_{o}(\mathrm{~kg})$ & $C_{o}(\mathrm{kN} /(\mathrm{mm} / \mathrm{s}))$ & $m_{u}(\mathrm{~kg})$ & $\mathrm{C}_{\mathrm{u}}(\mathrm{kN} /(\mathrm{mm} / \mathrm{s}))$ \\
\hline 15051 & 0.00425 & 50 & 0.01107 & 14378 & 0.00492 & 1400 & 0.0979 \\
\hline
\end{tabular}

In order to validate the simple mechanical model introduced in Fig. 7, $x_{o}$ has been calculated by solving the equation of motion (6), and is compared in Fig. 11 with the experimental response of the typical test presented in Fig. 10. The experimental values of $x_{u}$ are used as input data in solving Eq. (6). The results show excellent agreement between the two values of $x_{o}$ both during and after the impact, thus validating the simple mechanical model of the rack. Comparisons for 30 tests are reported in [13].

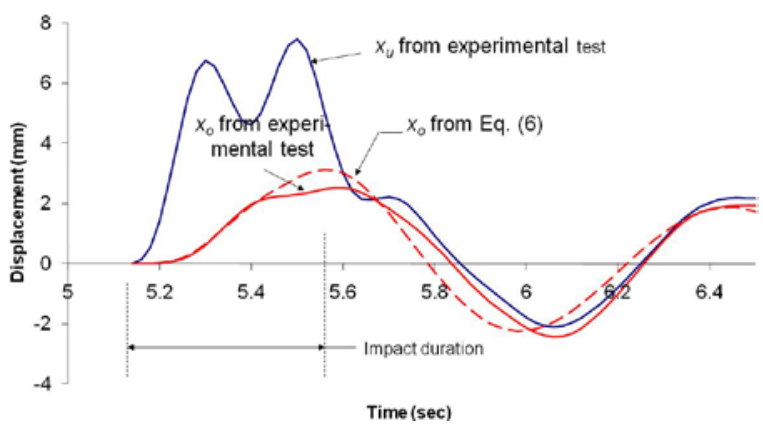

Fig. 11: Comparison between calculated and experimental values of $x_{O}$

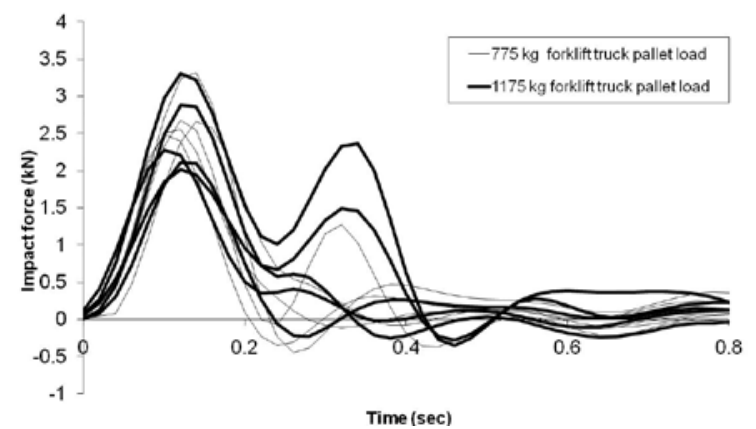

Fig. 12: Impact forces for the $1^{\text {st }}$ loading configuration; $775 \mathrm{kgs}$ and $1175 \mathrm{kgs}$ pallet loads

\subsection{Impact force}

The impact force $F_{\text {imp }}$ developing between the forklift truck and the drive-in rack can be calculated by solving Eq. (5) numerically using the experimental values of $x_{u}$ and $x_{o}$ as input data. Figure 12 shows the impact force $F_{\text {imp }}$ calculated using the average values of $k_{u}, m_{u}$ and $C_{u}$ given in Table 2 and Table 3 for 10 tests representing the $1^{\text {st }}$ loading configuration (empty bay). Detailed results can be found in [13]. As shown in Fig. 12, the impact force usually reaches its maximum between $0.1 \mathrm{sec}$ and $0.12 \mathrm{sec}$ for this loading configuration.

\section{FORKLIFT TRUCK AND RACK SYSTEM}

\subsection{The combined model}

One of the main aims of the research program is to calculate forklift truck impact forces and bay openings for different rack configurations, pallet loads and impact elevations. Such horizontal impact in the down-aisle direction is induced by the rotation of the forklift truck body about its front wheel axis.

Figure 13 shows the simple mechanical model of the forklift truck introduced in Fig. 5 rotated about the front wheel axis by an angle $\alpha$ corresponding to the initiation of impact. Beyond this point, further rotation of the mast and forks about the vertical axis will consist of additional rotation of the front wheel axis $(\alpha)$ and a twist of the mast relative to the front wheel axis $\left(\theta_{2}\right)$. Only the latter component of rotation is associated with damping $\left(C_{\mathrm{T}}\right)$ and stiffness $\left(k_{\mathrm{B}}\right)$. For small displacements and using geometrical relationships, the equations of motion (3) and (4) for $\theta_{2}$ and $\alpha$ become, 


$$
\begin{gathered}
m H_{C o G}\left(\left(\ell_{1}+\ell_{3}\right)-\frac{H_{C o G}}{H}\left(\ell_{1}+\ell_{2}\right)\right) \ddot{\theta}_{2}-\frac{k_{B}}{H}\left(\ell_{1}+\ell_{2}\right) \theta_{2}+m \frac{H_{C o G}^{2}}{H} \ddot{x}_{u}+\frac{k_{B}}{H} x_{u} \\
+m H_{C o G}\left(\left(\ell_{1}+\ell_{3}\right)-\frac{H_{C o G}}{H}\left(\ell_{1}+\ell_{2}\right)\right) \ddot{\alpha}-\frac{k_{B}}{H}\left(\ell_{1}+\ell_{2}\right) \alpha=-F_{i m p} H \\
m\left(\ell_{1}+\ell_{3}\right)\left(\left(\ell_{1}+\ell_{3}\right)-\frac{H_{C o G}}{H}\left(\ell_{1}+\ell_{2}\right)\right) \ddot{\theta}_{2}+k_{T} \theta_{2}+C_{T}\left|\dot{\theta}_{2}\right| \dot{\theta}_{2}+m \frac{H_{C o G}}{H}\left(\ell_{1}+\ell_{3}\right) \ddot{x}_{u} \\
+m\left(\ell_{1}+\ell_{3}\right)\left(\left(\ell_{1}+\ell_{3}\right)-\frac{H_{C o G}}{H}\left(\ell_{1}+\ell_{2}\right)\right) \ddot{\alpha}=-F_{i m p}\left(\ell_{1}+\ell_{2}\right)
\end{gathered}
$$

where $x_{u}$ is the horizontal down-aisle displacement at the point of impact. Equations (9) and (10) are valid while contact is maintained between the forklift truck and upright.

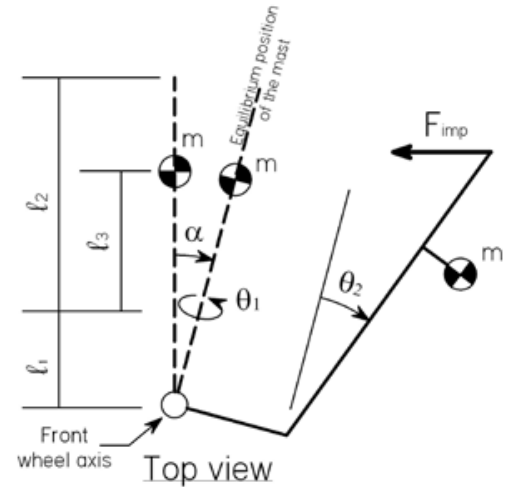

Fig. 13: Rotating motion of the forklift truck mechanical model

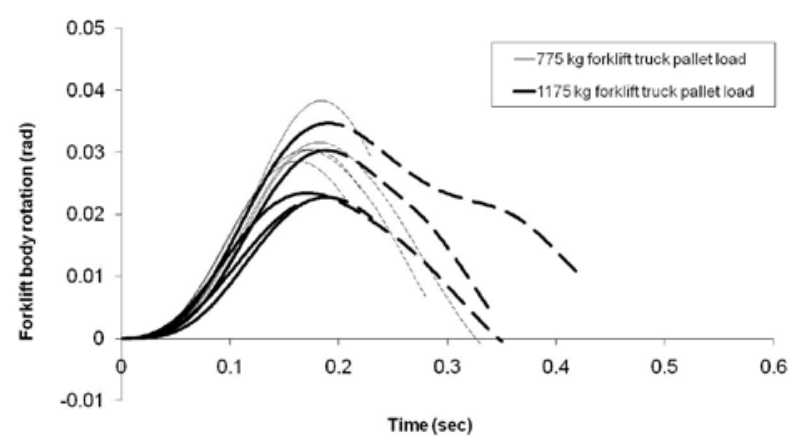

Fig. 14: Forklift truck body rotation $\alpha$ for the first loading configuration

\subsection{The forklift truck rotation $(\alpha)$}

The forklift truck body rotation $\alpha$ is obtained by solving Eqs. (9) and (10) using numerical methods with (i) $x_{u}$ taken from experimental impact test results, (ii) $F_{\text {imp }}$ calculated as per Section 3.4 and (iii) stiffness and damping values obtained from Table 2 and Table 3. Figure 14 shows $\alpha$ calculated for the 10 tests shown in Fig. 12. The curves are shown with solid lines in the validity range of Eqs. (9) and (10), i.e. when there is contact between the pallet and the rack, requiring the impact force $\left(F_{i m p}\right)$ to be positive. The results show that the variation of $\alpha$ is consistent for all tests and reaches its maximum value at about $0.15 \mathrm{sec}$.

After $0.15 \mathrm{sec}, \alpha$ is predicted to decrease. However, this result is not physically sound and simply reflects the loss of contact between the impacting pallet and the rack beyond the first phase of impact, where the bay opening attains its maximum, as discussed in Section 3.2.3. It is observed that $\alpha$ is still increasing when the maximum impact load is reached between 0.08 sec and 0.12 sec, see Fig. 12.

For the purpose of the reliability analysis described in Section 5, the distribution of the "maximum" forklift truck body rotation is calculated. This "maximum" rotation $\alpha$ is defined as the rotation at the crest of the curves shown in Fig. 14 and is calculated for 116 tests. The obtained distribution for the maximum forklift truck body rotation is shown in Fig. 15 and a beta distribution is found to provide the best fit. The average value of $\alpha$ is equal to $0.023 \mathrm{rad}$ with a COV of 0.46 . 


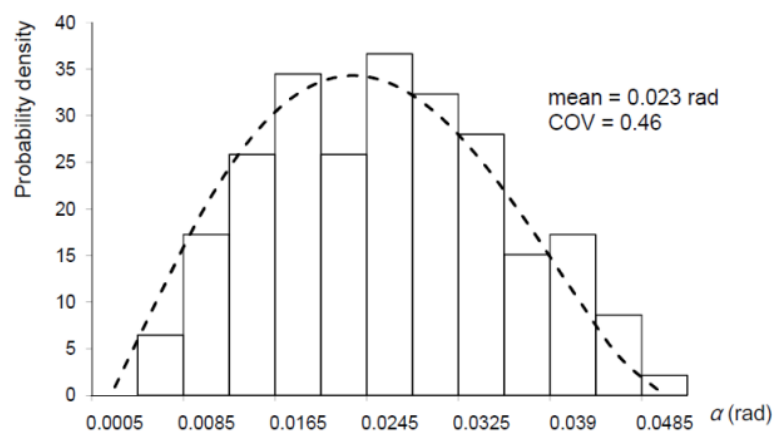

Fig. 15: Maximum forklift truck body rotation $\alpha$ (fitted to a Beta distribution)

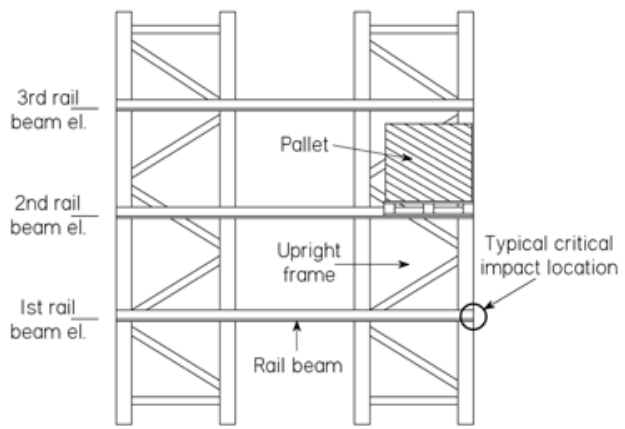

Fig. 16: The least favourable loading pattern: single pallet loading (side view)

\subsection{Dynamic FE analysis and parametric studies}

A finite element model has been calibrated against static tests performed by applying horizontal forces at various locations on the full-scale drive-in rack introduced in Section 3.2. The finite element model includes non-linear moment-rotation behaviour for the portal beam to upright and base plate to floor connections. The in-plane stiffness of the timber pallets is also included in the model. Non-linear geometric analyses were carried out using Abaqus [15]. The finite element model was shown to accurately capture the 3D behaviour of the tested unloaded and loaded racks (see [16-17]).

As detailed in Sections 4.1 and 4.2, the rotation of the forklift truck body is essentially the same for all impacts and can be taken as a common input for the combined mechanical model of the forklift truck (see Fig. 5) and rack model (see Fig. 7). The first $0.15 \mathrm{sec}$ of the impact was shown to represent the critical phase where the bay opens to a maximum, suggesting that only the first $0.15 \mathrm{sec}$ of the impact needs to be investigated. Consequently, the forklift truck mechanical model presented in Fig. 5 is now included in the abovementioned finite element model of the rack, and the base of the truck is rotated by the mean body rotation $\alpha$ defined from Fig. 14 to simulate the impact during the first 0.15 sec. Impact forces and bay openings can be extracted from the analyses for any drive-in rack configuration.

The finite element model combining the tested drive-in rack with the forklift truck model was first shown to provide a satisfactory representation of the experimental impact tests. The combined model was then used for parametric studies to analyse the influence on the bay opening of the height of the rack, the design unit load, the loading configuration, the friction between pallets and rail beams, the rack depth and the impact elevation. In the parametric study, 23 drive-in racks with heights varying from 3 metres to 12 metres and unit loads varying from $200 \mathrm{kgs}$ to $1200 \mathrm{kgs}$ (including pallet mass) were designed in accordance with current industry practice using the proprietary software RAD [18] and subjected to forklift truck impact. Rail beams were spaced every 1.5 metres in height.

The results show that [16-17]:

- Impacts at the lower rail beam elevation tend to be more severe than impacts at higher rail beam elevations leading to larger bay openings. This result, which may be counter intuitive, is mainly explained by the fact that the effective stiffness of the forklift truck decreases with the height of the impact because the rotational stiffness $k_{B}$ is constant.

- Racks designed to carry heavy loads are less likely to fail than racks designed to carry light loads. The greater the load, the stiffer the upright because of the stabilising effect of pallets. Thus, pallets lead to high impact loads but small bay openings.

- Tall racks (more than 6 metres high) are more sensitive to impact than short racks. 
- The loading configuration (i.e. the number of pallets in the vicinity of the impacted upright) has a significant impact on the bay opening. This is noticeable even for a small amount of friction between pallets and rail beams (coefficient of friction greater than $0.05)$.

\section{DESIGN FOR HORIZONTAL IMPACT}

A design procedure has been proposed for drive-in racks subjected to horizontal impact forces. The procedure is based on a structural reliability assessment of the bay opening occurring during impact, taking into account the uncertain nature of the impact force, structural resistance and structural analysis modelling. In design practice, the bay opening is determined from factored impact forces, and is not to exceed specified limits.

As mentioned in Section 4.3, in the presence of friction between rail beams and pallets, higher pallet loads generally result in higher impact forces but smaller bay openings. Yet, when friction is ignored, as is current industry practice, a single pallet loading pattern would result in the largest bay opening and is therefore the least favourable loading pattern. When the impact occurs there will be no pallet located at the impact point, since otherwise the forklift cannot access that particular elevation. Consequently, it is the pallets directly above or below the impact point that drop through. Thus, the bay opening should be checked at the elevations directly above/below the impact point. Figure 16 demonstrates the most unfavourable loading pattern and impact location.

\subsection{Impact force}

Although it would be possible for an engineer to perform the dynamic analysis presented in Section 4.3 to check the maximum bay opening, it would be impractical to require such type of analysis as part of a routine design procedure. From a structural design point of view, it is more appropriate to use an equivalent static force which produces the same (maximum) bay opening as that produced by the dynamic impact force.

An equation for such equivalent static design impact force was derived by analysing 36 typical drive-in racks, representing the current inventory of drive-in racks in Australia, using the dynamic finite element model. For each rack, impacts were simulated at different rail beam elevations, assuming a single pallet load pattern. A total of 100 representative impact scenarios were analysed (see [16]). Based on the study, a simple equation for calculating the equivalent static impact force $F_{\text {imp }}$ is proposed as,

$$
F_{\text {imp }}=4.94 \frac{\alpha L k_{1}}{1+0.1 k_{1} / k_{2}}
$$

where $\alpha$ is the forklift truck body rotation angle and $L$ is the horizontal distance from the bottom hinge of the mast of the forklift truck to the impact point $\left(\ell_{1}+\ell_{2}\right.$ in Fig. 5). The two terms $k_{1}$ and $k_{2}$ are defined as,

$$
k_{1}=\frac{E I H_{r}}{H_{i}^{2}\left(H_{r}-H_{i}\right)^{2}} \text { and } k_{2}=\frac{\omega}{H_{i}+d_{C o G}}
$$

in which $E I$ is the bending stiffness of the impacted upright, $H_{r}$ is the total height of the rack, $H_{i}$ is impact height, $\omega$ is the pallet load carried by the forklift truck, and $d_{C o G}$ is the centre of gravity of the forklift truck pallet load, measured from the bottom of the pallet. 


\subsection{Reliability analysis}

5.2.1 Limit state function and reliability target

Considering a pallet in a typical drive-in rack as illustrated in Figs 17(a) and (b), the bearing width of the pallet $\delta_{1}$ of the impacted upright is reduced to

$$
\delta_{1}^{\prime}=\delta_{1}-\Delta
$$

when the bay opens by $\Delta$ as a result of impact. Assuming the pallet will drop through if $\delta_{1} \leq 0$ and omitting the subscript " 1 " for simplicity, the system limit state function $g$ can be defined, as

$$
g=\delta-\Lambda
$$

such that failure will occur when $g \leq 0$.

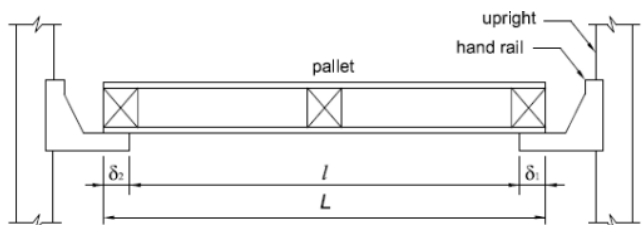

(a)

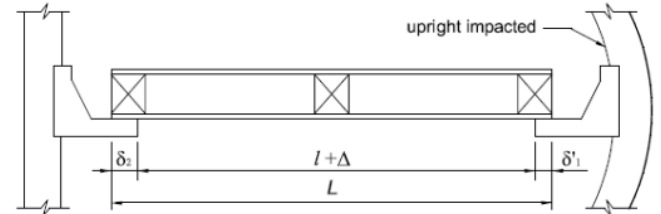

(b)

Fig. 17: Pallet bearing width

The two terms $\delta$ and $\Delta$ in Eq. (14) are random variables while for design practice, a deterministic format for Eq. (14) is needed. Although the drop-through limit state is similar to the ordinary serviceability limit state which is usually checked under unfactored loads, the consequence of the drop-through failure may be catastrophic, and so the limit state has the nature of an ultimate limit state. Therefore, an impact load factor $\gamma$ (greater than 1) is introduced in the proposed design check. The proposed conformance check takes the form,

$$
\gamma \Lambda_{n} \leq \delta_{a}
$$

in which $\gamma \Delta_{n}$ represents the bay opening calculated with factored design impact force and nominal structural properties, and $\delta_{a}$ is a (deterministic) allowable bay opening. The purpose of the load factor $\gamma$ is to take into account the uncertainties in the impact force, structural properties and models used in the structural analysis, and to achieve a desired target of structural reliability.

The acceptable probability of structural failure $P_{f}$ for rack structures is assumed in this study to be $2.0 \times 10^{-4} / \mathrm{yr}$, a value consistent with that of a typical steel member. In deriving the impact load factor, a range of probabilities $P(\mathrm{I})$ of impact occurring corresponding to occurrence rates between $10^{-2}$ and $2 / \mathrm{rack} / \mathrm{yr}$ was considered (see [19] for more details), thus allowing the reliability index to be calculated using the customarily expression,

$$
\beta=-\Phi^{-1}\left(P_{f} / P(\mathrm{I})\right)
$$

in which $\Phi()$ is the standard normal distribution function.

\subsubsection{Statistical properties and selection of impact load factor}

The impact force is characterized by high uncertainty which arises from two sources: the model uncertainty [19] and the inherent randomness of the basic variables (e.g., the forklift truck body rotation). Among the physical factors affecting the impact force $F$, the following variables are treated as random: $\omega$ (the weight of the pallet load carried by the forklift truck), $E I$ (the bending stiffness of the impacted upright), and $\alpha$ (the "maximum" forklift truck body rotation during the impact). The probability distributions of $\omega$ and $E I$ available in the literature [20] are used in this study, while the probability distribution of the forklift truck body rotation $\alpha$ is given in Fig. 15. 
The bounds of the pallet bearing width ( $\delta$ in Eq. (14)) can be readily obtained from manufacturing specifications for a given system. In typical Australian industry practice, the design bearing width of the pallet is around $60 \mathrm{~mm}$ with the bearing width found to vary between 40 $\mathrm{mm}$ to $80 \mathrm{~mm}$. In general, let $\delta_{n, \min }$ (or $\delta_{a}$ in Eq. (15)) and $\delta_{n, \max }$ denote the minimum and maximum design pallet bearing width, respectively. The pallet bearing width is assumed in this study to be uniformly distributed between these two extreme values.

The load factor $\gamma$ was expected to depend on the ratio of the actual pallet bearing width to the minimum allowable bearing width, $\delta / \delta_{a}$ [19], with the term $\delta / \delta_{a}$ being uniformly distributed with a lower bound of 1 and an upper bound of $\delta_{n, \max } / \delta_{n, \min }$ (or $\delta_{n, \max } / \delta_{a}$ ). Three representative values, $\delta_{n, \max } / \delta_{n, \min }=1.5,2.0$ and 2.5, are considered in determining the impact load factor. With known statistics for $\delta$ and impact force $F$, and assuming an acceptable failure probability of $2.0 \times 10^{-4} / \mathrm{yr}$, the load factor $\gamma$ has been determined [19] for impact occurrence rates varying between $10^{-2}$ and $2 /$ rack/yr. The results are summarised in Table 4 , which also shows the reliability index $\beta$ corresponding to the assumed values of failure probability $P_{f}$ and probability of impact $P(\mathrm{I})$ as per Eq. (16).

Table 4: Impact load factor $\gamma$

\begin{tabular}{ccccccc}
\hline Occurrence rate $(/ \mathrm{rack} / \mathrm{yr})$ & $P(\mathrm{I})$ & $P(\mathrm{~g} \leq 0 \mid \mathrm{I})$ & $\beta$ & $\gamma^{a}$ & $\gamma^{b}$ & $\gamma^{c}$ \\
\hline $10^{-2}$ & 0.010 & $2.01 \times 10^{-2}$ & 2.05 & 1.77 & 1.61 & 1.52 \\
$10^{-1}$ & 0.095 & $2.10 \times 10^{-3}$ & 2.86 & 2.21 & 2.09 & 2.02 \\
0.5 & 0.393 & $5.08 \times 10^{-4}$ & 3.29 & 2.43 & 2.33 & 2.27 \\
1 & 0.632 & $3.16 \times 10^{-4}$ & 3.42 & 2.49 & 2.40 & 2.35 \\
2 & 0.865 & $2.31 \times 10^{-4}$ & 3.50 & 2.53 & 2.44 & 2.39 \\
\hline
\end{tabular}

Values are based on a target risk $P_{f}=2 \times 10^{-4} / \mathrm{yr}$.

${ }^{\mathrm{a}} \delta_{n, \max } / \delta_{n, \min }=1.5,{ }^{\mathrm{b}} \delta_{n, \max } / \delta_{n, \min }=2.0,{ }^{\mathrm{c}} \delta_{n, \max } / \delta_{n, \min }=2.5$

Table 4 shows that the load factor $\gamma$ is relatively insensitive to the $\delta_{n, \max } / \delta_{n, \min }$ ratio and that it falls within the range of 2.0 to 2.5 for occurrence rates between $10^{-1}$ and $1 / \mathrm{rack} / \mathrm{yr}$. On this basis, a single factor, $\gamma=2.3$, appears to be satisfactory across a large range of impact occurrence rates.

5.2.3 Design procedure

The proposed probability-based checking procedure can be summarised as follows:

- Calculate the nominal impact load $F_{n}$ using Eq. (11) with a nominal truck body rotation of $0.023 \mathrm{rad}$ (mean value). The design impact load is obtained by multiplying the nominal impact load $F_{n}$ by the load factor $\gamma$ of 2.3.

- Apply the factored impact load assuming the least favourable loading pattern (single pallet load pattern) and impact location (first or second rail beam elevation).

- Calculate the bay opening $\gamma \Delta_{n}$ under the factored impact load, and check the compliance with the minimum pallet bearing width (Eq. (15)).

\section{CONCLUSIONS}

This paper describes the calibration of simple mechanical models for predicting the dynamic behaviour of forklift trucks and drive-in racking systems under horizontal impact. A mechanical model of the combined system of a forklift truck and a drive-in rack is also derived and shown to accurately predict observed impact behaviour. Tests were conducted to determine the mass, stiffness and damping characteristics of the forklift truck and rack system, followed by tests on a full-scale drive-in rack subjected to impact by a forklift truck. 
The experimental observations were used to calibrate finite element models of the combined forklift truck and drive-in rack system. Parametric studies were carried out to determine the bay opening for a wide range of racking systems, leading to a series of conclusions on the rack configurations and impact elevations most likely to cause drop-through failure of pallets under impact. An equation was derived for determining the equivalent static force producing the same bay opening as the maximum bay opening determined from a transient dynamic analysis. This equation was combined with a reliability analysis of the drop-through limit state to determine an appropriate value of load factor for a range on impact occurrence rates. This concluded in the formulation of a simple limit states design procedure for drive-in racks subject to horizontal impact forces.

\section{References}

[1] T. Pekoz, G. Winter, "Cold-formed steel rack structures", Proceedings of the 2nd Specialty Conference on Cold-Formed Steel Structures (Ed.: W.W. Yu), St Louis, Missouri, USA, 603-615, 1973.

[2] RMI, Specification for the design, testing and utilization of industrial steel storage racks, Rack Manufacturers Institute, Charlotte, U.S.A., 2008.

[3] EN 15512, Steel static storage systems - Adjustable pallet racking systems - Principles for structural design, European Committee for Standardization (CEN), Brussels, Belgium, 2009.

[4] AS 4084, Steel storage racking, Standards Australia, Sydney, Australia, 1993.

[5] SEMA, Code of practice for the design of static rack, Storage Equipment Manufacturers' Association, London, UK, 1980.

[6] FEM 10.2.07, Version 0.12 - Draft - The Design of 'Drive in' and 'Drive through' pallet racking, Federation Europeenne de la Manutention, Brussels, Belgium, 2010.

[7] N.W. Murray, "Stability analysis of drive-in racking storage systems", Proceedings of the International Conference on Structural Stability and Design (Eds.: S. Kitipornchai, G.J. Hancock, M.A. Bradford), Sydney, Australia, 189-195, 1995.

[8] L. Dunai, T. Hegedus, L. Kaltenbach, S. Adany, "Experimental and numerical studies on the stability of racking frames", Proceedings of the 5th International Colloquium on the Stability and Ductility of Steel Structures (Eds.: T. Usami, Y. Itoh), Nagoya, Japan, 647-652, 1997.

[9] M.A. Salmon, R.E. Welch, A. Longinow, "Analysis of drive-in and drive-thru storage racks", Proceedings of the 2nd Specialty Conference on Cold-Formed Steel Structures (Ed.: W.W. Yu), St Louis, Missouri, U.S.A., 617-639, 1973.

[10] A.M.S. Freitas, M.S.R. Freitas, F.T. Souza "Analysis of steel storage rack columns", Journal of Constructional Steel Research, 61, 1135-1146, 2005.

[11] A.M.S. Freitas, F.T. Souza, M.S.R. Freitas, "Theoritical-experimental analysis of industrial storage racks Drive-in in cold formed steel members", Proceedings of the International Colloquium on Stability and Ductility of Steel Structures (Eds.: D. Camotim, N. Silvestre, P.B. Dinis), Lisbon, Portugal, 373-380, 2006.

[12] B.P. Gilbert, The behaviour of steel drive-in racks under static and forklift truck impact forces, PhD Thesis, School of Civil Engineering, The University of Sydney, Sydney, Australia, 2010.

[13] B.P. Gilbert, K.J.R. Rasmussen, "Determination of accidental forklift truck impact forces on drive-in steel rack structures", Research Report R902, School of Civil Engineering, The University of Sydney, Australia, 2009.

[14] B.P. Gilbert, K.J.R. Rasmussen "Determination of accidental forklift truck impact forces on drive-in steel storage rack structures", Engineering Structures, In Press, 2011.

[15] Abaqus, Abaqus ver. 6.5-4 - User manual, (ABAQUS, Inc.), Providence, U.S.A., 2005.

[16] B.P. Gilbert, K.J.R. Rasmussen, H. Zhang, "Impact tests and parametric impact studies on drive-in steel storage racks", Research Report R903, School of Civil Engineering, The University of Sydney, Australia, 2009.

[17] B.P. Gilbert, K.J.R. Rasmussen, "Impact tests and parametric impact studies on drive-in steel storage racks", Engineering Structures, In press, 2011.

[18] Dematic, RAD - User manual, (Dematic, Pty. Ltd.), Sydney, Australia, 2006.

[19] H. Zhang, B.P. Gilbert, K.J.R. Rasmussen "Drive-in steel storage racks II: Reliability-based design for forklift truck impact", ASCE Journal of Structural Engineering, In Press, 2011.

[20] B.R. Ellingwood, T. Galambos, J.G. MacGregor, C.A. Cornell, "Development of a probability based load criterion for American National Standard A58", NBS special publication 577, National Bureau of Standards, Washington D.C., 1980. 